\title{
TRAINABILITY OF PLAYERS FROM THE BULGARIAN YOUTH NATIONAL FIELD HOCKEY TEAM
}

\author{
I. Bonova* \\ National Sports Academy "Vassil Levski”, Sofia, Bulgaria \\ Centre for Scientific and Applied Research in Sports
}

\begin{abstract}
PURPOSE: The aim of the study is to determine the sensitive windows related to motor skills development as well as the rate of trainability of the adolescent hockey players from the Bulgarian Youth National Field Hockey Team.

METHODS: This study included 20 adolescent field hockey competitors at the national level - boys at an average age of 13.5 years. The experiment was conducted twice with the same participants at an interval of 16 weeks. They were assigned into two groups: responsive and non-responsive. Those who achieved an improvement in two or more motor tests were included in the "responsive" group. Those who did not improve their performance in the motor tests were included in the group of "nonresponsive" players.

RESULTS: The findings from the study show that considering the age (13.5), aerobic and anaerobic conditioning is trainable $\left(\mathrm{VO}_{2}\right.$ max and $30 \mathrm{~m}$ speed test).

DISCUSION: The responsive group was determined to be of high and slow trainability, while the nonresponsive one - of low and slow trainability, hence the prospects of the latter for staying in the national team are not favorable.
\end{abstract}

CONCLUSION: It can be recommended that the head coach select only players of medium level trainability for the 2020 Summer Championship.

Key words: Bulgarian National Team, trainability, youth hockey players

\section{INTRODUCION}

Human talent includes many components. One of them, which is especially important in sports, is that certain athletes respond to the training process faster and better than other, less talented ones. This ability of an athlete to react positively to training influences is defined as trainability $(1,2)$. We can point out two main factors of sports development: determinants of fitness related to heredity (trainability) and determinants of development related to training. J.M. Kotz (3) used as a basis the temporal nature of trainability for achieving a particular training effect (adaptation), thus distinguishing between the following types of trainability: high and fast;

\footnotetext{
*Correspondence to: Iveta Bonova, National Sports Academy “Vassil Levski”, Sofia, Bulgaria, Centre for Scientific and Applied Research in Sports, e-mail: csars_ibonova@nsa.bg,tel. 0892251349
}

high and slow; low and fast; low and slow. In order to develop specific qualities needed for performing well in a particular sport, these qualities must be genetically embedded in the future athlete, and the higher the initial level (of trainability), the higher the level to which they can be developed in the process of longterm training (adaptation).

In this line of reasoning, the process of selecting sports talents (children gifted in sports) is interrelated with the pace of development of motor skills during the key stages of development - childhood and adolescence. The degree of training adaptation as a result of well-planned and conducted sports training provides a clear indication of the level of trainability of a particular player.

Trainability best answers the question whether an adolescent player has sports potential (4). According to Viru et al., 1999 (5), a long-term 
model for the development of junior athletes should be focused on the following age periods:

$>8-11$ years: initial training;

$>12-16$ years: special sports training;

$>16-18$ years: competitive training;

$>$ over 18 years: sports mastery.

In this context, the age of 12-16 years is defined as a sensitive period for training and coaching. This is the period of athletes' development which provides valuable information about the level of motor skills trainability, but, of course, only as a result of the implementation of an appropriate training program which is based on trainees' agerelated and individual characteristics and is in accordance with the principle of optimal loading (6). In this aspect, trainability is regarded as a property of the athlete leading to faster adaptation to training loads and as a presence of genetic talents (7). Hendriks, S.,
2012 (8) defined trainability as the susceptibility of developing athletes to training stimuli at different stages of their development. He identified the "windows" of trainability of five trainable components: endurance, strength, speed, flexibility and technical skills. Sensitive periods of training for endurance and strength are based on the initial boost of growth and peak growth rate, while the windows of training for speed, technical skills and flexibility are based on chronological age.

\section{A MODEL OF FIELD HOCKEY TRAINING IN BULGARIA}

According to Antonov, A., T. Dimitrieska (2013) (9), the model of long-term sports training in field hockey in Bulgaria includes six stages. With the exception of the first stage - preliminary training - and the last one mastery, all other stages take place within two sports years (Table 1).

Table 1. Levels of field hockey training (according to A. Antonov, Dimitrieska, 2013)

\begin{tabular}{|l|c|c|c|}
\hline \multicolumn{1}{|c|}{$\begin{array}{c}\text { Levels of } \\
\text { training }\end{array}$} & $\begin{array}{c}\text { Age } \\
\text { (years) }\end{array}$ & Group & $\begin{array}{c}\text { Term of the training } \\
\text { (calendar years) }\end{array}$ \\
\hline $\begin{array}{l}\text { Level 1. } \\
\text { Preliminary }\end{array}$ & $8-10$ & Children under 10 years (U10) & $2+$ \\
\hline $\begin{array}{l}\text { Level 2. } \\
\text { Beginners }\end{array}$ & $11-12$ & Children under 12 years (U12) & 2 \\
\hline $\begin{array}{l}\text { Level 3. } \\
\text { Orientation }\end{array}$ & $13-14$ & $\begin{array}{c}\text { Boys and girls under 14 years } \\
\text { (U14) }\end{array}$ & 2 \\
\hline $\begin{array}{l}\text { Level 4. } \\
\text { Specialization }\end{array}$ & $15-16$ & Youths under 16 (U16) & 2 \\
\hline $\begin{array}{l}\text { Level 5. } \\
\text { Advanced }\end{array}$ & $17-18$ & $\begin{array}{c}\text { Youths under 18 (U18) } \\
\text { Level 6. Mastery } \\
- \text { juniors } \\
- \text { seniors } \\
- \text { veterans }\end{array}$ & $\begin{array}{c}\text { 19-21 } \\
22-35\end{array}$ \\
\hline
\end{tabular}

Note: Each calendar year includes one sports season.

As the author of the program for long-term development of adolescent hockey players, Antonov, A. (2005), (10) has reported that the applied model is based on comprehensive physical, technical, tactical and psychological preparation. The complex combination of strength, speed, endurance, speed, agility, aerobic and anaerobic conditioning and body composition is a necessary part of hockey training, since all movements on the field are carried out mainly by running with different intensity and frequent change of direction, and less often by walking. Moreover, every technical action, with or without a ball, is performed with the hockey stick. Considering the dynamics, intensity and volume of movements of the modern hockey player, the level of trainability is undoubtedly of great importance for making sports achievement (11). 
The appropriate combination of training loads for the development of motor skills provides the effect of transfer of adaptation and facilitates the overall training process. The hockey game requires a rich "arsenal" of specific technical skills for dribbling the ball, shooting at a goal, overcoming an opponent, and others. Tactical skills include: visual scanning, recognizing the opponent's tactics, anticipation skills, quick decision-making and action in defense or offense.

Field hockey is one of the dynamic sports games with two officially regulated disciplines: outdoor (hockey 11) and indoor (hockey 6). When playing outdoor hockey, within 60 minutes hockey players run more than $9 \mathrm{~km}$, which requires good physical training (12).

According to Dimitrieska, T., A. Antonov, 2013, (12) indoor hockey requires a high level of speed and strength qualities and speed endurance. In a study of the competitive load of 16-year-old hockey players, it was found that during the first half-time hockey players sustained $82 \%$ of the maximum heart rate (167 bpm), and $85 \%$ of the maximum heart rate in the second half-time (173 bpm). High values of heart rate indicate that when optimizing the methods and means in the process of training, the high anaerobic requirements of athletes should be taken into account as they are present in $60 \%$ of the game time.

The aim of the study is to determine the sensitive windows related to motor skills development as well as the rate of trainability of the adolescent hockey players from the Bulgarian Youth National Field Hockey Team. The subject of the study was adolescent (U$15)$ field hockey players.

\section{METHODS}

This study included 20 national adolescent players - boys at an average age of 13.9 years (12.6 - 15 years). The study was carried out twice with the same individuals, over a period of 16 weeks. The location of the study was the same as was the order of the tests. The participants in this study performed the following test program: height, weight, right and left handgrip strength, long jump, Beep test and $30 \mathrm{~m}$ speed run.
Height and weight were measured with the same technical means, the long jump was recorded with an accuracy of $1 \mathrm{~cm}$. Handgrip strength was measured by using the TKK digital hand dynamometer (TKK 5101 Grip-D, Japan), and the individual optimal grip span was calculated for each child prior to testing by using the equations for girls and boys between the ages of 12 and 18 years (13). The software, specialised for children, this being BeepShuttle Junior (14), was applied to administer the $20 \mathrm{~m}$ multistage fitness test with the original 1-minute protocol, as described by Leger et al. (15), and to calculate the estimated maximal oxygen uptake $\left(\mathrm{VO}_{2}\right.$ max). In order to assess the $\mathrm{VO}_{2}$ max of the participants, Beep Shuttle Junior also computed the percentile score for each individual based on age- and gender-specific international norms (16, 17).

The statistical analyses were conducted with SPSS Statistics 17, IBM, USA software, using descriptive statistics and the Shapiro-Wilk test of normality. All parameters showed a normal distribution, they were compared by using the Paired Sample t-test and effect size to determine the level of change.

\section{STATISTICS}

Statistical analysis of the initial data shows that the sample has a normal distribution (ShapiroWillk). Statistical processing has been performed by the method of pairwise comparisons and has shown that there is statistical reliability for the following measured indicators: height, weight, $\mathrm{VO}_{2}$ max and standing long jump. Effect size was observed in order to determine the level of trainability, from which we found a mean effect for aerobic $\left(\mathrm{VO}_{2} \max \right)$ and anaerobic alactic conditioning (30 m speed run).

\section{RESULTS}

Depending on their individual performance, the studied adolescent field hockey players were divided into two groups: responsive and nonresponsive. Players who had registered growth in two or more motor tests were included in a group of the "responsive" ones, i.e., those susceptible to training load and strain. The second group included players who did not improve their performance when performing the motor tests; this group was defined as "nonresponsive". Table 2 presents the results of the anthropometric and motor tests. 
BONOVA I.

Table 2. Anthropometric parameters and physical fitness tests of the adolescent hockey players

\begin{tabular}{|c|c|c|c|c|c|c|}
\hline Paired Sample Test & $\begin{array}{l}\text { Responsive } \\
\text { group } \\
\text { n=10; } \pm \text { SD }\end{array}$ & $\begin{array}{l}\text { Sig. }(2- \\
\text { tailed) }\end{array}$ & Effect size & $\begin{array}{l}\text { Non- } \\
\text { responsive } \\
\text { group } \\
\mathbf{N}=\mathbf{1 0} ; \pm \text { SD }\end{array}$ & $\begin{array}{l}\text { Sig. (2- } \\
\text { tailed) }\end{array}$ & Effect size \\
\hline Age (years), first & $13,4 \pm 0,9$ & ,487 & Small & $13,2 \pm 0,5$ & ,034 & Medium \\
\hline Age (years), second & $13,5 \pm 1,2$ & ,487 & Small & $13,5 \pm 0,5$ &, 034 & Medium \\
\hline Height $(\mathrm{cm})$, first & $163,4 \pm 9,4$ &, 006 & Small & $161,2 \pm 9,2$ &, 052 & Very small \\
\hline Height $(\mathrm{cm})$, second & $165,0 \pm 9,8$ & ,006 & Small & $162,1 \pm 9,2$ & ,052 & Very small \\
\hline Weight (kg), first & $54,9 \pm 9,7$ & ,049 & Small & $60,4 \pm 8,2$ &, 002 & Medium \\
\hline Weight $(\mathrm{kg})$, second & $57,4 \pm 10,5$ &, 049 & Small & $64,6 \pm 8,9$ &, 002 & Medium \\
\hline $\begin{array}{l}\text { Handgrip strength test } \\
\text { (kg), first }\end{array}$ & $31,1 \pm 6$ & ,218 & Small & $28,9 \pm 6,3$ & ,598 & Very small \\
\hline $\begin{array}{l}\text { Handgrip strength test } \\
(\mathrm{kg}) \text {, second }\end{array}$ & $32,2 \pm 6,5$ & ,218 & Small & $29,5 \pm 6,4$ & ,598 & Very small \\
\hline $\mathrm{VO}_{2} \max (\mathrm{ml} / \mathrm{kg} / \mathrm{min})$, first & $58,5 \pm 2,7$ & ,046 & Medium & $48,9 \pm 4,7$ & , 187 & Very small \\
\hline $\begin{array}{l}\mathrm{VO}_{2} \max (\mathrm{ml} / \mathrm{kg} / \mathrm{min}) \\
\text { second }\end{array}$ & $59,9 \pm 3,8$ & ,046 & Medium & $48,0 \pm 4,5$ &, 187 & Very small \\
\hline $\begin{array}{l}\text { Standing long jump }(\mathrm{cm}) \text {, } \\
\text { first }\end{array}$ & $200 \pm 15$ & ,037 & Small & $153,8 \pm 19,6$ & ,977 & Very small \\
\hline $\begin{array}{l}\text { Standing long jump }(\mathrm{cm}) \text {, } \\
\text { second }\end{array}$ & $203 \pm 16$ & ,037 & Small & $153,7 \pm 19,1$ & ,977 & Very small \\
\hline $\begin{array}{l}30 \mathrm{~m} \text { speed run test, } \\
\text { first }\end{array}$ & $6,01 \pm 0,3$ & ,186 & Medium & $5,8 \pm 0,6$ & 372 & Small \\
\hline $\begin{array}{l}30 \mathrm{~m} \text { speed run test, } \\
\text { second }\end{array}$ & $5,9 \pm 0,4$ & ,186 & Medium & $5,7 \pm 0,3$ & 372 & Small \\
\hline
\end{tabular}

The analysis of the results shows that considering the age (13.5 years), aerobic and anaerobic conditioning is trainable $\left(\mathrm{VO}_{2} \max\right.$ and $30 \mathrm{~m}$ speed test). Figure 1 presents a comparative graph of the dynamics of the changes in the aerobic conditioning $\mathrm{VO}_{2}$ max in the group of responsive players. We can observe a regular increase in $\mathrm{VO}_{2}$ max, with a $2.4 \%$ percentage increase in the responding group.

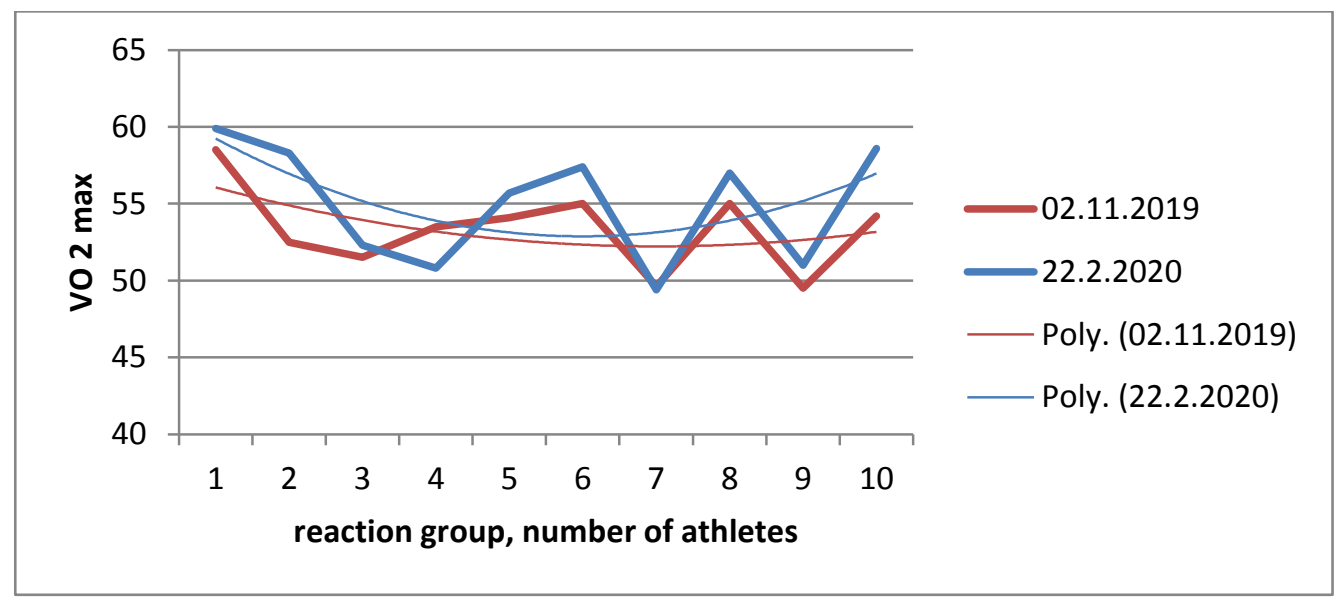

Figure 1. Trainability of the $\mathrm{VO}_{2}$ max of adolescent hockey players

\section{DISCUSSION}

The present study was performed with a dependent sample within a period of 16 weeks. The percentage increase in aerobic conditioning was only $2.4 \%$ and the level of trainability was estimated as medium. In the non-responsive group, no increase in aerobic conditioning was observed and the level of trainability (the size effect) was estimated as small. Therefore, the responsive players can be defined as a group with low and fast trainability in terms of $\mathrm{VO}_{2}$ max, and the non-responsive ones as a group with low 
BONOVA I.

and slow trainability. The average effect size reveals two facts: 1. The studied age of 13.5 years is a "sensitive window" in terms of developing the aerobic capacity of adolescent athletes; 2. The small percentage increase indicates that the winter training was not conducted according to the approved training program for adolescent field hockey players.

A well-controlled study with adolescent football players reported an increase of $6-$ $11 \%$ in $\mathrm{VO}_{2}$ max over a period of 10 weeks (18). Most training programs for the development of aerobic capacity have duration of 5 to 12 weeks and include $15-20$ training sessions for the targeted development of oxygen consumption.

The growth rate in the speed of the responsive group in the $30 \mathrm{~m}$ speed run is $1,7 \%$, which is hardly impressive. The effect size over the 16week training period was estimated as a medium, and the level of trainability was thus determined as low and fast. In the group of the non-responsive players no changes were observed regarding the results of the $30 \mathrm{~m}$ speed run test, and the effect size of the changes was estimated as small (Table 2), i.e., these are adolescent athletes with low and slow trainability.

Authors studying the windows of trainability related to speed have defined the age of 13-14 years as a second favorable period for the development of speed capabilities (Speed 2), associated with alactate power up to 20 seconds (19). Sports educators who work with children often report that children experience less fatigue during short-term, high-intensity exercise than mature athletes (20); therefore higher levels of trainability were expected in the present study. The low levels of trainability in terms of the tested aerobic and anaerobic conditioning could be due to shortcomings in the execution of the training sessions.

\section{CONCLUSIONS}

The responsive group was determined as one of low and fast trainability, while the nonresponsive group had the least favourable prognosis in terms of trainability, based on the studied motor abilities. Head coaches may be recommended to select players from the responsive group.

The windows of trainability require priority work for developing a specific motor quality.
They are based on chronological and biological age, which is why an individual approach is necessary in adolescent athletes' training. The age of $11-16$ years is defined as sensitive in terms of growth in sports results. Missed training and coaching at this age can hardly be compensated.

The results obtained from the sportspedagogical testing have indicated that the studied contingent did not purposefully perform the training program during the winter 4-month preparatory period.

\section{REFERENCES}

1. Issurin, V., Retrospective analysis of long term preparation of outstanding athletes for earlier identification of athletic talent. Sports Science, 2, pp 40- 44, 2015.

2. Issurin, V. Training in XXI century. Sport Publishing House. Moscow. (in Russian), 2016.

3. Kotz, J.M., Sports Physiology. Fizkultura i Sport (in Russian), 1986.

4. Pfeiffer, K, Lobelo, F., Pate, R., Endurance trainability of children and youth. Book, 2007.

5. Viru, A., Loko, L., Harro, M., Laaneots, I., Critical periods in the development of performance capacity during childhood and adolescence. Eur J Phys Educ;4 (1):75$119,1999$.

6. Dick, F., Sports, training, principles. Book, London, 2006.

7. Bailey, R., Cardinal, C., Higgs, C., Norris, S., Way, R., Long term athlete development in sport- Canadian sport for life. Canadian sports centres, 2005.

8. Hendriks, S., Trainability of junior rugby union players. S Afr J SM 2012; 24(4):122126. DOI:10.7196/SAJSM.357, 2012.

9. Antonov, A., Dimitrieska, T., Standards for planning, control and evaluation of hockey sports training, NSA Press, Sofia. (in Bulgarian), 2013.

10.Antonov, A., Mini-hockey - training, technique, rules and guidelines. Avangard, Prima, Sofia. (in Bulgarian), 2005.

11. Antonov, A., A classification model and characteristic of technical skills in field hockey, BFHT, Avangard, Sofia. (in Bulgarian), 2007.

12. Dimitrieska, T., Antonov, A., Characteristics of the heart rate in 16-yearold hockey players during indoor play. IX International Scientific Conference of 
Department "Football and Tennis", NSA, pp. 34-38, Avangard Prima, Sofia. (in Bulgarian), 2013.

13. Ruiz et. al. (2006) Optimal grip span for adolescents (13-18 years) according to hand size. Journal Hand Surgery, American; 31(8):1367-72, 2006.

14. Kolimechkov, S., Petrov, L., Aleksandrova, A. \& Cholakov, K., BeepShuttle Junior: Software for the Administration of the $20 \mathrm{~m}$ Shuttle Run Test in Children and Adolescents. Journal of Advanced Sport Technology, 1, 35-40, 2018.

15. Leger, L., Lambert, J., Goulet, A., Rowan, C. \& Dinelle, Y., [Aerobic capacity of 6 to 17-year-old Quebecois-20 meter shuttle run test with 1 minute stages]. Can J Appl Sport Sci, 9, 64-9, 1984.

16. Miguel-Etayo, P., Gracia-Marco, L., Ortega, F., Inteman, T., Foraita, L., Lissner, L., Oja, L., Barba, G., Michels, N, Tornaritis, M., Molnar, D., Pitsiladis, Y.,

\section{BONOVA I.}

Ahrends, W. \& Moreno., L., Physical fitness reference standards in European children: the IDEFICS study. International Journal of Obesity, 38, 57-66, 2014.

17. Tomkinson, G. R., Lang, J. J., Tremblay, M. S., Dale, M., Leblang, A. G., Belanger, K., Ortega, F. B. \& Leger, L., International normative $20 \mathrm{~m}$ shuttle run values from 1 142026 children and youth representing 50 countries. Br J Sports Med., 2016.

18. Sperlich, B., De Marees, M., Koehler, K., et all., Effects of 5 weeks of high-intensity interval training vs. volume training in 14year- old soccer players. Journal Strength, Conditioning and Research, 25:1271-1278, 2011.

19. Ford, P., Croix, M., Lloyd, R., Meyers, R., Moosavi, M., Oliver, J., Till, K., Williams, C., (2011) Journal of Sports Sciences, 29 (4):389-402, 2011.

20. Hebestreit, H., Bar - Or, O., The young athlete. Oxford, pp.18-26, 2008. 